\title{
Environmental barriers, activity limitations and participation restrictions experienced by people with major limb amputation
}

\author{
Pamela Gallagher', Mary-Ann O'Donovan², Anne Doyle ${ }^{2}$ and \\ Deirdre Desmond ${ }^{3}$
}

\begin{abstract}
Background: Limited research is available that explores major limb amputation and the World Health Organization's International Classification of Functioning, Disability and Health (ICF).

Objectives: To investigate the barriers, participation restriction and functioning levels experienced by people with a major limb amputation.

Study design: Secondary data analysis.

Method: Relevant data for I 48 people with major limb amputation were extracted from the National Physical and Sensory Disability Database in Ireland.

Results: The most common environmental barriers encountered were climate, physical environment and income. Participation restriction was most commonly experienced in sports/physical recreation, leisure/cultural activity and employment/job-seeking. For daily activities and functioning, the most common difficulties were with standing for long periods, walking long distances and the emotional effects of disability. Differences were found between people with an upper limb or lower limb prosthesis.

Conclusion: This paper addresses the limited information available on environmental barriers, activity limitation and participation restriction of people with a major limb amputation. Greater understanding of the impact of amputation and prosthesis type on activity, participation and environmental barriers is important to facilitate improved management and planning at the individual, service and societal level.
\end{abstract}

\section{Clinical relevance}

Improved understanding of environmental barriers and challenges, activity limitations and participation restrictions experienced by individuals with major limb amputation is a critical step in informing evidence-based service delivery, intervention and policy in order to improve outcomes for this group.

\section{Keywords}

Prosthetics, amputation, ICF, participation, barriers, activities

Date received: 2I November 20I0; accepted: 22 March 201 I

\section{Introduction}

The World Health Organization's International Classification of Functioning and Health $(\mathrm{ICF})^{1}$ is an important framework through which our understanding of the interactions between people and their environment, participation and activities can be enhanced. To date, explicit references to the ICF in the field of amputation have been limited to reviews of existing outcome measures according to their applicability to

\footnotetext{
'Dublin City University, Ireland.

${ }^{2}$ Health Research Board, Ireland.

${ }^{3}$ National University of Ireland Maynooth, Ireland.

Corresponding author:

Pamela Gallagher, Dublin City University, School of Nursing, Faculty of Science and Health, Dublin 9, Ireland

Email: pamela.gallagher@dcu.ie
} 
an ICF group. $^{2-4}$ Some studies have indirectly addressed individual aspects of the ICF, particularly body impairment and activity limitation. However, to the best of our knowledge, only one study ${ }^{5}$ has investigated environmental barriers. Furthermore, the few studies relating to participation are confined to specific participation restrictions, such as leisure. ${ }^{6}$

Currently, work is underway to develop an ICF core set for persons following an amputation. As outlined by Kohler et al., 'an important basis for the optimal acute and long-term management of amputees is an in-depth understanding of the patient and the functional consequences of the amputation, systematic and detailed consideration of the patient and their environment and sound measurement of functional outcomes for the different sites and levels of amputation'. ${ }^{7}$ While there has been clear and growing recognition of the need to systematically document and investigate these issues, relatively little data is available as yet.

The aim of this paper is to describe the environmental barriers, participation restrictions and functioning levels experienced by people with a major limb amputation in Ireland. Here we extract data from the National Physical and Sensory Disability Database in Ireland to characterize the experiences in these domains of people with limb amputation.

\section{Methods}

\section{Measurements}

The National Physical and Sensory Disability Database (NPSDD) in Ireland provides a comprehensive information base for decision-making and priority setting related to planning, funding and managing services for people with physical or sensory disabilities who currently require or receive specialized health and personal social services. ${ }^{8}$ Specialized health and personal social services are defined as 'the range of health and personal social services, additional to generic services, which may be required by people with physical or sensory disabilities for the purpose of achieving health and social gain and maximum quality of life'(Gallagher, 2000). ${ }^{9}$ These include therapeutic and rehabilitation services; personal assistance and support services; day, respite and residential services; and technical aids and appliances. Registration on the database is voluntary. The cut-off point for registration on the NPSDD is age 65 years; individuals older than 65 are under the remit of the Department of Health and Children's Older Peoples Services in Ireland.

Drawing on the World Health Organization's International Classification of Functioning, Disability and Health (ICF), ${ }^{1}$ the Measure of Activity and Participation (MAP) module of the database (described in detail below) aims to relate service needs to environmental barriers, activity limitations and participation restrictions. In line with the ICF definition of disability as outlined in O'Donovan et al., ${ }^{8}$ the MAP reflects interactions between activity limitations (as measured by the WHODAS 2.0) and the environment. Participation restriction in life activities reflects the level of disability the person experiences.

Regional database teams are responsible for collecting NPSDD data throughout Ireland from people who meet the eligibility criteria. The information is input into a centralized web-based system that can be accessed nationally and regionally for analysis and reporting. When people consent to being included in the database, they consent to the subsequent use of non-identifying information for research purposes. Data on the MAP is collected according to a standard protocol by the individual's key worker or, in the absence of a key worker, by a data collector, as part of the interview for the NPSDD. (Additional information on the NPSDD is available in O'Donovan et al. ${ }^{8}$ ) The MAP section of the form is only completed by people aged 16 years or over.

The MAP section of the NPSDD data form consists of three parts:

1. The 'barriers and challenges' section highlights the social-environmental factors that potentially serve to exclude or restrict participation of people with disabilities in society and attempts to ascertain whether these identified factors act as barriers or challenges to participation of the people included in the NPSDD over a period of 12 months (from date of data form completion). There are nine items (see Table 1), each with a yes/no response.

2. The 'participation' section identifies the extent to which an individual's participation has been restricted in 13 life areas, such as education, employment, socializing, shopping and family life (see Table 2). Responses are measured on a five-point rating scale from 'not at all' to 'severely'. Respondents are also asked to indicate the extent to which this experience of restriction has bothered them (not at all, a little, a lot).

3. The World Health Organization Disability Assessment Schedule 2.0 (WHODAS 2.0) is a standardized measure that captures the extent of activity limitation experienced by an individual and is conceptually compatible with the ICF. ${ }^{10}$ Psychometric testing of the WHODAS 2.0 has been rigorous and extensive. Using the 12-item form (see Table 3), it is a measure of the difficulty the individual has had performing particular daily activities over the 
Table I. The number and percentage of people experiencing environmental barriers and challenges.

\begin{tabular}{|c|c|c|c|c|c|c|c|c|c|}
\hline \multirow[b]{2}{*}{ Barriers \& challenges } & \multicolumn{2}{|c|}{$\begin{array}{l}\text { Amputation } \\
(n=\mid 48)\end{array}$} & \multicolumn{2}{|c|}{$\begin{array}{l}\text { Upper prosthesis } \\
(n=17)\end{array}$} & \multicolumn{2}{|c|}{$\begin{array}{l}\text { Lower prosthesis } \\
(n=65)\end{array}$} & \multicolumn{2}{|c|}{$\begin{array}{l}\text { Type of prosthesis } \\
\text { not specified }(n=65)\end{array}$} & \multirow{2}{*}{$\begin{array}{l}\text { Difference across } \\
\text { upper and lower } \\
\text { prosthesis } \\
\text { Fisher's exact tes }\end{array}$} \\
\hline & $n$ & $\%$ & $n$ & $\%$ & $n$ & $\%$ & $n$ & $\%$ & \\
\hline Physical environment & 81 & 54.7 & 4 & 23.5 & 37 & 56.9 & 39 & 60.0 & $p<.027$ \\
\hline Services \& supports & 32 & 21.6 & 2 & 11.8 & 13 & 20.0 & 16 & 24.6 & NS \\
\hline Access to information & 60 & 40.5 & 6 & 35.3 & 23 & 35.4 & 31 & 47.7 & NS \\
\hline People's attitudes & 39 & 26.4 & 2 & 11.8 & 19 & 29.2 & 17 & 26.2 & NS \\
\hline Transport & 55 & 37.2 & 6 & 35.3 & 21 & 32.3 & 27 & 41.5 & NS \\
\hline $\begin{array}{l}\text { Laws, regulations, } \\
\text { entitlements }\end{array}$ & 55 & 37.2 & 9 & 52.9 & 23 & 35.4 & 23 & 35.4 & NS \\
\hline Income & 76 & 51.4 & 8 & 47.1 & 29 & 44.6 & 38 & 58.5 & NS \\
\hline Climate & 82 & 55.4 & 6 & 35.3 & 36 & 55.4 & 40 & 61.5 & NS \\
\hline Personal characteristics & 11 & 7.4 & 2 & 11.8 & 4 & 6.2 & 5 & 7.7 & NS \\
\hline
\end{tabular}

Table 2. The number and percentage of people who have experienced some restriction (mild, moderate, severe, extreme) in areas of participation relevant to them across each of the groups.

\begin{tabular}{|c|c|c|c|c|c|c|c|c|c|}
\hline \multirow[b]{2}{*}{ Participation restriction } & \multicolumn{2}{|c|}{$\begin{array}{l}\text { Amputation } \\
(n=148)\end{array}$} & \multicolumn{2}{|c|}{$\begin{array}{l}\text { Upper prosthesis } \\
(n=17)\end{array}$} & \multicolumn{2}{|c|}{$\begin{array}{l}\text { Lower prosthesis } \\
(n=65)\end{array}$} & \multicolumn{2}{|c|}{$\begin{array}{l}\text { Type of prosthesis } \\
\text { not specified }(n=65)\end{array}$} & \multirow{2}{*}{$\begin{array}{l}\text { Difference across } \\
\text { upper and lower } \\
\text { limb prosthesis } \\
\text { Fisher's exact test }\end{array}$} \\
\hline & & $\%$ & $n$ & $\%$ & $n$ & $\%$ & $n$ & $\%$ & \\
\hline Education and training & $37 / 80$ & 46.3 & $4 / 11$ & 36.4 & $12 / 37$ & 32.4 & $21 / 31$ & 67.7 & NS \\
\hline $\begin{array}{l}\text { Employment or job } \\
\text { seeking }\end{array}$ & $66 / 96$ & 68.8 & $11 / 12$ & 91.7 & $23 / 43$ & 53.5 & $32 / 41$ & 78.0 & $p<.019$ \\
\hline Community life & $38 / 108$ & 35.2 & $0 / 13$ & 0 & $17 / 45$ & 37.8 & $21 / 50$ & 42.0 & $p<.006$ \\
\hline Family life & $56 / 144$ & 38.9 & $7 / 17$ & 41.2 & $21 / 64$ & 32.8 & $28 / 62$ & 45.2 & NS \\
\hline Socializing & $62 / 144$ & 43.1 & $4 / 17$ & 23.5 & $30 / 65$ & 46.2 & $27 / 61$ & 44.3 & NS \\
\hline Shopping & $63 / 139$ & 45.3 & $6 / 17$ & 35.3 & $23 / 64$ & 35.9 & $33 / 57$ & 57.9 & NS \\
\hline Living with dignity & $53 / 139$ & 38.1 & $6 / 17$ & 35.3 & $20 / 62$ & 32.3 & $26 / 59$ & 44.1 & NS \\
\hline Leisure/cultural activities & $70 / 135$ & 51.9 & $7 / 17$ & 41.2 & $33 / 61$ & 54.1 & $29 / 56$ & 51.8 & NS \\
\hline $\begin{array}{l}\text { Sports or physical } \\
\text { recreation }\end{array}$ & $91 / 124$ & 73.4 & $5 / 13$ & 38.5 & $44 / 56$ & 78.6 & $42 / 55$ & 76.4 & $p<.007$ \\
\hline Religion & $25 / 122$ & 20.5 & $2 / 16$ & 12.5 & $8 / 53$ & 15.1 & $14 / 52$ & 26.9 & NS \\
\hline Hospital services & $30 / 136$ & 22.1 & $2 / 16$ & 12.5 & $15 / 60$ & 25.0 & $12 / 59$ & 20.3 & NS \\
\hline Mental health services & $7 / 33$ & 21.2 & $\mathrm{I} / \mathrm{I}$ & 100 & $4 / 21$ & 19.0 & $2 / 11$ & 18.2 & NS \\
\hline $\begin{array}{l}\text { Community-based } \\
\text { health services }\end{array}$ & $20 / 142$ & 14.1 & $1 / 17$ & 5.9 & $8 / 62$ & 12.9 & $11 / 62$ & 17.7 & NS \\
\hline
\end{tabular}

previous 30 days. In addition, the individual is asked to what extent these difficulties have interfered with his/her overall life in those previous 30 days. The WHODAS 2.0 is unique in its potential to determine the level of functioning of an individual irrespective of the type of disability or diagnosis.

\section{Sample}

All individuals registered with the NSPDD are under 66 years of age and require or are receiving a specialized health and/or personal social service related to their disabling condition. For this paper, we extracted data for people who met the following criteria: (a) having had a major limb amputation, (b) being at least 16 years of age (to comply with MAP requirements) and (c) having completed the MAP.

\section{Analysis}

SPSS version 17.0 was used to analyse the data. Descriptive statistics were used for counts and frequencies. Percentages are based on the number of people 


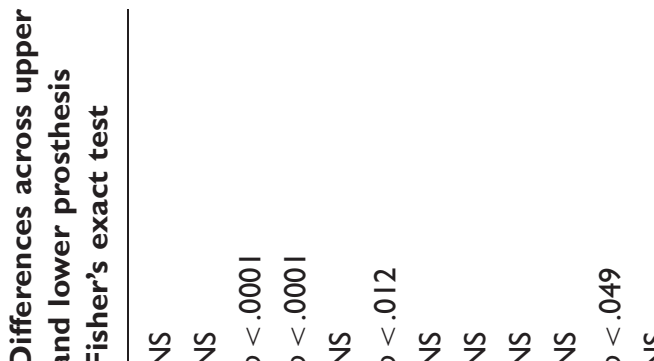

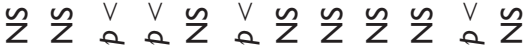

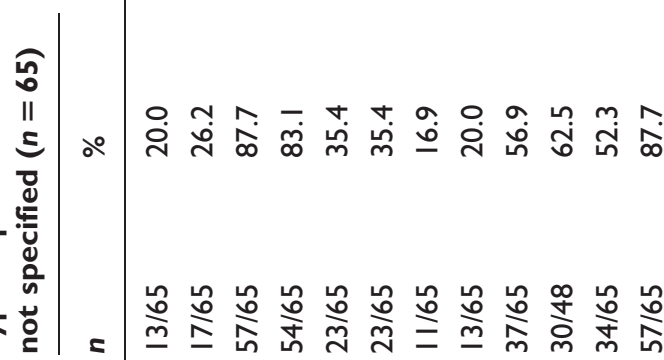

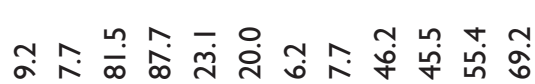

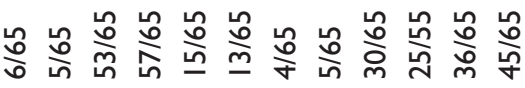

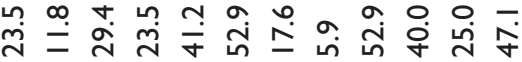

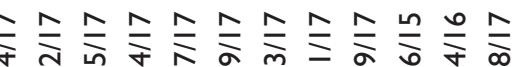

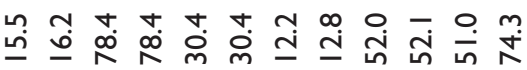

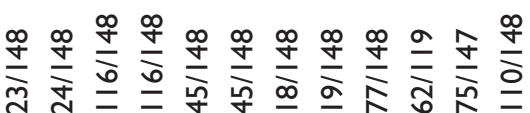

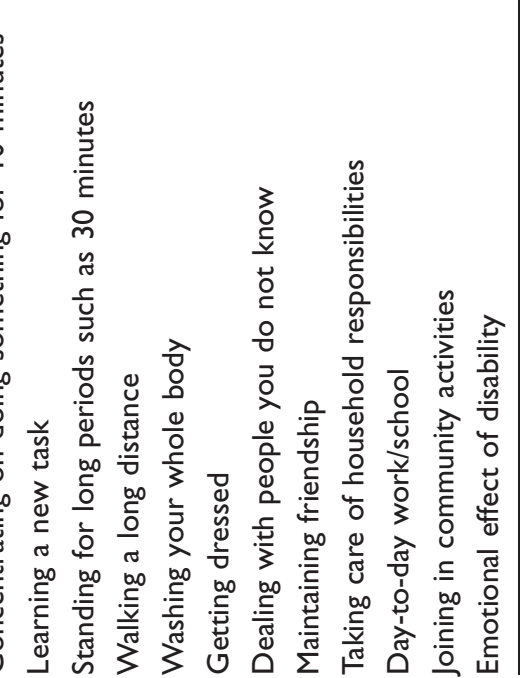

who deemed the item applicable to themselves. Participation restriction can be experienced as mild, moderate, severe or extreme. For analysis in this paper, these categories are collapsed into the single category 'some restriction' for reasons of parsimony, as the focus of interest in this paper is the experience of restriction irrespective of level. Similarly, the responses to WHODAS II items were collapsed into one category denoted 'some difficulty'. Data are included for the total group of people who had a major limb amputation, those who clearly specified that they used or required an upper or a lower prosthesis, and those who did not specify upper or lower prosthetic use/ requirement. Fisher's exact tests were undertaken to explore whether there were significant associations between upper or lower limb prosthesis use and each of the barriers, participation restrictions and activities and functioning. Fisher's exact test is used in place of the chi-square test in 2-by-2 contingency tables with small sample sizes.

\section{Results}

The number of people in the MAP dataset with amputation as their primary or secondary diagnostic category was 148 . Of these 148 people, $65(43.9 \%)$ used or required a lower limb prosthesis, $17(11.5 \%)$ used or required an upper limb prosthesis, 1 used both an upper and lower limb prosthesis, and 65 people (43.9\%) did not specify the type of prosthesis. The age groups and gender of the 148 individuals are documented in Table 4; the majority being males aged 40-59 years.

Table 1 shows the numbers who said yes to experiencing a barrier/challenge within each group. Taking the amputation group as a whole, the top three barriers for people with an amputation were climate $(55.4 \%)$, the physical environment $(54.7 \%)$ and income $(51.4 \%)$. This matched the top three for people requiring a lower limb prosthesis, whereas the

Table 4. Age group and gender breakdown of people with an amputation $(n=148)$.

\begin{tabular}{|c|c|c|c|c|c|c|}
\hline \multirow[b]{3}{*}{ Age (years) } & \multicolumn{4}{|c|}{ Gender } & & \\
\hline & \multicolumn{2}{|c|}{ Female } & \multicolumn{2}{|c|}{ Male } & \multicolumn{2}{|c|}{ Total } \\
\hline & $n$ & $\%$ & $n$ & $\%$ & $n$ & $\%$ \\
\hline$\leq 24$ & 3 & 7.9 & 4 & 3.6 & 7 & 4.8 \\
\hline $25-39$ & 6 & 15.8 & 27 & 24.5 & 33 & 22.3 \\
\hline $40-59$ & 19 & 50.0 & 54 & 49.1 & 73 & 49.3 \\
\hline $60-65$ & 10 & 26.3 & 25 & 22.7 & 35 & 23.6 \\
\hline Total & 38 & 100.0 & 110 & 100.0 & 148 & 100.0 \\
\hline
\end{tabular}


top three for people with an upper limb prosthesis were laws, regulations and entitlements $(52.9 \%)$, income $(47.1 \%)$ and access to information, transport and climate (all 35.3\%). People with a lower limb prosthesis were significantly more likely $(p<.027)$ than people with an upper limb prosthesis to experience the physical environment as a barrier or challenge.

Table 2 shows the number and percentage of people with an amputation who had experienced some participation restriction (mild, moderate, severe or extreme). Areas where they most commonly experienced some participation restriction were sports or physical recreation $(73.4 \%)$, leisure/cultural activities $(51.9 \%)$ and employment or job seeking $(68.8 \%)$. For individuals with a lower limb prosthesis, areas of participation restriction included sports or physical recreation (78.6\%), leisure/cultural activities (54.1\%) and employment or job seeking $(53.5 \%)$ ). For people with an upper limb prosthesis, the most common areas were employment or job seeking $(91.7 \%)$, family life $(41.2 \%)$ and leisure/cultural activities (41.2\%). Those with lower limb prostheses were significantly more likely than those with upper limb prostheses to experience some restriction in community life $(p<.006)$ and sports or physical recreation $(p<.007)$ and less likely to experience restriction in employment or job seeking $(p<.019)$.
For people with a lower limb prosthesis, difficulties were experienced with walking a long distance $(87.7 \%)$, standing for long periods such as 30 minutes $(81.5 \%)$, and the emotional effect of disability $(69.2 \%)$. For people with an upper limb prosthesis, the areas most likely to present difficulty included getting dressed $(52.9 \%)$, maintaining friendship $(52.9 \%)$ and the emotional effect of disability (47.1\%). Lower limb prosthesis users were more likely than upper limb prosthesis users to experience difficulty walking a long distance $(p<.0001)$, standing for long periods $(p<.0001)$ and joining in community activities $(p<.049)$. However, upper limb prosthesis users were significantly more likely to experience difficulty getting dressed $(p<.012)$.

Tables 5 and 6 report WHODAS 2.0 global questions across the various groups and illustrate the number of days people experienced difficulty, the number of people experiencing difficulty daily and the extent to which these difficulties interfered with their lives. The average number of days per month that people experienced difficulties with lower versus upper limb prostheses were 19.48 and 18.65 , respectively. Approximately $41 \%$ of those with an upper limb prosthesis and $43 \%$ with a lower limb prosthesis reported that these difficulties interfered severely or extremely with their lives.

Table 5. Mean number of days people experienced difficulty.

\begin{tabular}{|c|c|c|c|c|}
\hline & \multicolumn{4}{|c|}{ Number of days difficulties were present } \\
\hline & $\begin{array}{l}\text { Amputation } \\
(n=148)\end{array}$ & $\begin{array}{l}\text { Upper prosthesis } \\
(n=17)\end{array}$ & $\begin{array}{l}\text { Lower prosthesis } \\
(n=65)\end{array}$ & $\begin{array}{l}\text { Type of prosthesis } \\
\text { not specified }(n=65)\end{array}$ \\
\hline M & 22.00 & 18.65 & 19.48 & 25.28 \\
\hline SD & 12.43 & 14.40 & 13.19 & 10.37 \\
\hline Range & $1-30$ & $2-30$ & $1-30$ & $2-30$ \\
\hline $\begin{array}{l}\text { Number of people who reported } \\
\text { difficulties every day }\end{array}$ & 102 & 10 & 38 & 53 \\
\hline $\begin{array}{l}\text { Number of people who reported } \\
\text { no days with difficulty or did not } \\
\text { answer the question }\end{array}$ & 24 & 5 & 12 & 7 \\
\hline
\end{tabular}

Table 6. Overall how did these difficulties interfere with your life?

\begin{tabular}{|c|c|c|c|c|c|c|c|c|c|}
\hline & \multicolumn{2}{|c|}{$\begin{array}{l}\text { Amputation } \\
(n=148)\end{array}$} & \multicolumn{2}{|c|}{$\begin{array}{l}\text { Upper prosthesis } \\
(n=I 7)\end{array}$} & \multicolumn{2}{|c|}{$\begin{array}{l}\text { Lower prosthesis } \\
(n=65)\end{array}$} & \multicolumn{2}{|c|}{$\begin{array}{l}\text { Type of prosthesis not } \\
\text { specified }(n=65)\end{array}$} & \multirow{2}{*}{$\begin{array}{l}\text { Differences across } \\
\text { upper and lower } \\
\text { - prosthesis } \\
\text { Fisher's exact test }\end{array}$} \\
\hline & $n$ & $\%$ & $n$ & $\%$ & $n$ & $\%$ & $n$ & $\%$ & \\
\hline $\begin{array}{l}\text { Overall how did these } \\
\text { difficulties } \\
\text { interfere with your life? }\end{array}$ & $|3|$ & 88.5 & 13 & 76.5 & 55 & 84.6 & 62 & 95.4 & NS \\
\hline
\end{tabular}




\section{Discussion}

At least one in five people with a major limb amputation experienced each of the environmental barriers captured in the NPSDD as challenges. At least one in five experienced services and supports as an environmental barrier. Approximately one in four experienced people's attitudes as an environmental barrier and at least one in two people with an amputation experienced the physical environment, income and climate as an environmental barrier. Ephraim et al. ${ }^{5}$ also reported that the greatest perceived barriers for individuals with limb loss were in the physical/structural environment. With regard to climate as a key environmental challenge, a residual limb can be sensitive to climate changes. For example, perspiration can impact on the physical comfort of the limb, while wet leaves or snow on the ground can impact on mobility and consequently on participation in activities. ${ }^{11}$ While sports or physical recreation, leisure/cultural activities and employment or job seeking were the most common areas of participation restriction, it is important to note that $36 \%$ of people with a major limb amputation experienced difficulty in living with dignity. Furthermore, nearly three out of four people with a major limb amputation experienced difficulty due to the emotional effect of the disability. Cardol et al. ${ }^{12}$ also identified emotional distress as an important variable explaining restrictions in participation.

Differences in the environmental barriers, participation restrictions and activity limitations experienced by those with a lower limb versus an upper limb prosthesis reflect experiential and practical differences between these conditions. Of note is the finding that people with a lower limb prosthesis experience greater restriction in community activities and difficulty in joining in community activities than people with an upper limb amputation. This may be explained by the fact that people with a lower limb prosthesis are more likely to experience the physical environment as a barrier or challenge than people with an upper limb prosthesis. To participate in community activities, sufficient mobility and the ability to gain access easily are important facilitating factors.

The NSPDD is a comprehensive national database regarding the specialized health services currently used or needed by people with physical/sensory disability. However, due to specific eligibility criteria and voluntary registration, the NSPDD is not representative of the entire population with disabilities in Ireland. Furthermore, because the database incorporates a wide spectrum of physical and sensory disabilities and focuses primarily on service provision, it is neither practical nor possible to ask detailed questions relating to a specific condition (e.g. type of amputation, cause of amputation, length of time with prosthesis). Participants are not asked specifically about their type of prosthesis but more generally about technical aids and appliances. It is therefore possible, as in the current sample, that participants do not view their prosthesis as a technical aid or appliance and consequently do not list it as such. Furthermore, as there is a limit to the technical aids and appliances that can be listed on the database form, participants may possibly prioritize other technical aids and appliances when completing the form. It is also important to note the imbalance in numbers in upper limb and lower limb prosthesis groups; although this is similar to the prevalence of upper and lower limb amputations reported internationally. Nonetheless, the data presented here contributes to our understanding of the environmental barriers, activity limitations and participation restrictions experienced by people with a major limb amputation. Furthermore, the results of this study represent a first step in the use and implementation of the ICF with people with a major limb amputation.

Focusing on major limb amputation highlights the common experiences of restriction and barriers to participation in society for this group. In addition, it illustrates the link between this experience and the impact of service interventions. The prescription of a prosthetic device is an intervention of specific relevance for people with a major limb amputation. Heinemann and Pape ${ }^{13}$ have reported that the effective use of assistive technology can improve functional independence and afford a greater opportunity for societal participation and integration. However, Scherer and Glueckauf ${ }^{14}$ argue that understanding and assessing the influences and value of technology on activities and participation are insufficiently studied. The need for an evidence base to support and direct the provision of informed, efficient and responsive services is clear. To fully examine the impact of services on participation, it would be useful to look at (a) the full range of services (including the type and use of a prosthesis) currently used and needed by an individual with a major limb amputation, and (b) the environmental barriers, activity limitations and experience of participation when accessing and using these services. This information could be used to track differences in participation experiences as services and environmental barriers change and evolve over time.

\section{Conclusion}

The findings of this study enhance our understanding of environmental barriers and challenges, activity limitations and participation restrictions of people with major limb amputation. More particularly, they highlight the differing profiles in these domains of people with upper versus lower limb amputation. Only in 
recent times has the scope and possibility of research in the ICF opened up. According to Cerniauskaite et al., ${ }^{15}$ 'viewing disability as an interaction between health condition and environmental factors is the key to how disability can be measured, and how interventions to reduce it can be evaluated'. The basic premise behind the MAP tool is to provide information on the impact of service interventions for people with disabilities, for example people with a major limb amputation, in order to improve their level of participation in those areas of life from which they feel wholly or partially excluded. It is beneficial to identify areas and barriers as well as the services that prove effective in bringing about improvement. ${ }^{16}$ Being able to describe major limb amputation and disability at the level of the body, activity limitation, participation restriction and environmental barrier provides an important holistic perspective for identifying appropriate evidence-based policy and interventions, and also provides a benchmark to assess the impact of such policy and interventions at both individual and societal level. In addition, the availability of data allows social inequalities to be addressed, such as difficulty in living with dignity.

\section{Funding}

This research received no specific grant from any funding agency in the public, commercial or not-for-profit sectors.

\section{References}

1. World Health Organization. ICF: International Classification of Functioning, Disability and Health. Geneva: World Health Organization, 2001.

2. Deathe AB, Wolfe DL, Devlin M, Hebert JS, Miller WC and Pallaveshi L. Selection of outcome measures in lower extremity amputation rehabilitation: ICF activities. Disabil Rehabil 2009; 31(18): 1455-73.

3. Lindner HY, Nätterlund BS and Hermansson LM. Upper limb prosthetic outcome measures: review and content comparison based on International Classification of Functioning, Disability and Health. Prosthet Orthot Int 2010; 34(2): 109-28.

4. Hebert JS, Wolfe DL, Miller WC, Deathe AB, Devlin M and Pallaveshi L. Outcomes measures in amputation rehabilitation: ICF body functions. Disabil Rehabil 2009; 31(19): 1541-54.
5. Ephraim PL, MacKenzie EJ, Wegener ST, Dillingham TR and Pezzin LE. Environmental barriers experienced by amputees: the Craig Hospital Inventory of Environmental Factors-Short Form. Arch Phys Med Rehabil 2006; 87(3): 328-33.

6. Couture M, Caron CD and Desrosiers J. Leisure activities following a lower limb amputation. Disabil Rehabil 2010; 32(1): 57-64.

7. Kohler F, Cieza A, Stucki G, Geertzen J, Burger H, Dillon MP, et al. Developing core sets for persons following amputation based on the International Classification of Functioning, Disability and Health as a way to specify functioning. Prosthet Orthot Int 2009; 33(2): 117-29.

8. O'Donovan MA, Doyle A and Gallagher P. Barriers, activities and participation: Incorporating ICF into service planning datasets. Disabil Rehabil 2009; 31(25): 2073-80.

9. Gallagher P. Final Report of the National Physical and Sensory Disability Database Development Committee. Dublin, Ireland: Health Research Board, 2002.

10. Epping-Jordan J and Üstün TB. The WHODAS II: levelling the playing field for all disorders. WHO Bulletin of Mental Health 2000; 6: 4-5.

11. Gallagher P and MacLachlan M. Adjustment to an artificial limb: A qualitative perspective. Journal of Health Psychology 2001; 6(1): 85-100.

12. Cardol M, de Jong BA, van den Bos GAM, Beelen A, de Groot IJM and de Haan RJ. Beyond disability: perceived participation in people with a chronic disabling condition. Clin Rehabil 2002; 16: 27-35.

13. Heinemann A and Pape T. Coping and adjustment. In: Scherer M (ed.) Assistive technology: Matching device and consumer for successful rehabilitation. American Psychological Association, 2001, pp.123-53.

14. Scherer MJ and Glueckauf R. Assessing the benefits of assistive technologies for activities and participation. Rehabil Psychol 2005; 50(2): 132-41.

15. Cerniauskaite M, Quintas R, Boldt C, Raggi A, Cieza A, Bickenbach JE, et al. Systematic literature review on ICF from 2001 to 2009: its use, implementation and operationalisation. Disabil Rehabil 2011; 33(4): 281-309.

16. Doyle A and O'Donovan MA. Measure of Activity and Participation (MAP): The experience of people with neurological conditions. Dublin, Ireland: Health Research Board, 2008. 